\title{
Emisyon Kontrol Uygulamalarında Saf Pomza Taşı Kullanabilirliğinin Deneysel Olarak Araştırılması
}

\author{
Niyazi Yılmaz ÇOLAK ${ }^{1}$, Doğan ȘİMȘEK ${ }^{1 *}$ \\ ${ }^{1}$ Bitlis Eren Üniversitesi, Teknik Bilimler Meslek Yüksekokulu, Bitlis
}

\begin{abstract}
Özet
$\mathrm{Bu}$ çalışmada, tek silindirli bir dizel motorda egzoz emisyonlarına katalizör olarak saf pomza taşının kullanılabilirliği ve egzoz emisyonlarına etkileri deneysel olarak incelenmiştir. Egzoz emisyon karakteristiklerini belirlemek amacıyla motor tam gaz konumunda, değişik motor yüklerinde teste tabi tutulmuştur. Yapılan çalışma ile atmosferi kirleten ve sera gazı etkisi gösteren emisyonları filtre etmede pomza madeninin etkisi araştırılmış olup sonuçlar grafik olarak verilmiştir. Dizel motordan kaynaklanan zararlı gaz emisyonlarındaki değişim izlenmiştir. Elde edilen sonuçlarda standart katalizör kullanıldığında $\mathrm{HC}, \mathrm{CO}, \mathrm{NO}_{\mathrm{x}}$ ve is emisyonlarında sırası ile $\% 49, \% 48, \% 49$ ve $\% 26$ oranında bir azalma olduğu, katalizör olarak pomza kullanımında ise, $\% 19, \% 6, \% 2-3$ ve \%12-44 oranında bir azalma olduğu görülmüştür. Bu sonuçlar neticesinde pomza madeni oksitleyici ve $\mathrm{NO}_{\mathrm{X}}$ indirgeyici özelliğe sahip metal ve soy metaller ile desteklenmesi ile daha iyi sonuçlar elde edilebileceği görülmüştür.
\end{abstract}

Anahtar kelimeler: Pomza, Emisyon, Dizel Motor, Katalizör.

\section{Experimental Investigation of the Using Pure Pumice Stone In Emission Control Applications}

\begin{abstract}
In this study, the usability of pumice stone as catalyst for the exhaust emissions of a single cylinder diesel engine, and its effects on the exhaust emissions are investigated experimentally. The engine is tested under fully open throttle and various engine load conditions. In this study, the performance of pumice material in filtering the pollutant and greenhouse gas emissions is investigated and the results are presented graphically. Change in the harmful gas emissions exhausted from the diesel engine is observed. While $49 \%, 48 \%, 49 \%$ and $26 \%$ reductions in $\mathrm{HC}, \mathrm{CO}, \mathrm{NO}_{\mathrm{X}}$ and soot emissions are achieved by using standard catalyst, using pumice material provided reductions in these emissions as $19 \%, 6 \%, 2-3 \%, 12-44 \%$ respectively. Results showed that better results can be obtained by supporting pumice material by oxidizing and $\mathrm{NO}_{\mathrm{X}}$ reductive metals and noble metals.
\end{abstract}

Keywords: Pumice, Emission, Diesel Engine, Catalyst.

\section{Giriş}

Uzun yıllardır çevre bilincinin gelişmesi ile hava kirliliğinin azaltılması önem kazanmaktadır. Hava kirliliğinin başlıca sebepleri endüstri gazları, konut ısıtmaları sonucu oluşan gazlar, termik santraller ve motorlu taşıt emisyonlarıdır. Hava kirleticileri arasında motorlu taşıtlardan kaynaklanan egzoz emisyonları kirleticilerin önemli bir kısmını oluşturmaktadır [1]. Motorlu taşıtlar çevreyi; egzoz emisyonu, yakıt, yağ buharı, kursun bileşikleri, asbest ve lastik tozları, aşınma, paslanma ve korozyon sonucu oluşan gaz, sıvı ve katı atıklarla kirletmektedir. Bu kirleticilerin en etkin zararlı ve yoğun olanları egzoz gazında bulunan $\mathrm{CO}, \mathrm{HC}, \mathrm{NO}_{\mathrm{x}}$ ve $\mathrm{PM}$ (is, duman vb.) emisyonlarıdır. Bunlardan $\mathrm{NO}_{\mathrm{x}}$ ile $\mathrm{PM}$ emisyonları daha çok dizel motorlarından kaynaklanmaktadır [2]. Motorlu taşıtlardan kaynaklanan kirleticilerin özellikleri ve yoğunlukları motor tipine, motor ayarına, kullanım tarzına, yakıt bileşimine ve atmosferik şartlara bağlı olarak değişmektedir [3]. Toplu taşımacılıkta ve ağır yük taşıtlarında

*Sorumlu yazar: dsimsek@beu.edu.tr

Geliş Tarihi: 29/01/2017 Kabul Tarihi: 14/06/2017 
genellikle dizel motorlar kullanılmaktadır. Bu sebeple dizel motorlarından kaynaklanan emisyonların azaltılması önem kazanmaktadır [4].

Doğrudan ve dolaylı yoldan insan sağlığını ve çevreyi tehdit eden emisyonların kontrolü kaçınılmaz bir hal almaktadır. Gelişmiş ülkelerde motorlu taşıt emisyonlarına sınırlamalar getirilmiş ve bu bağlamda birçok standart geliştirilmiştir. Geliştirilen standartlar emisyonların maksimum değerlerini sınırlamış olup, bu değerlerin aşılması durumunda bir takım yaptırım unsurları içermektedir. Bu sebepten dolayı araştırmacılar içten yanmalı motorlarda egzoz emisyonlarının azaltılması konusunda birçok çalışma yapmaktadır. Yapılan bu çalışmalar doğrultusunda benzinli ve dizel motorlarda emisyon kontrol sistemleri geliştirilmiş olup, emisyonlara karşı bir takım önlemler alınmıştır [5]. Motorlu taşıtlarda egzoz emisyonlarının azaltılmasına yönelik olarak alınan önlemler üç kısımda toplanabilir:

1. Motor öncesinde alınan önlemler; yakıt bileşiminin iyileştirilmesi, alternatif yakıt kullanımı;

2. Motorda alınan önlemler; motorda yapısal olarak alınan önlemler;

3. Motor sonrasında alınan önlemler; egzoz gazındaki zararlı emisyonların azaltılmasına yönelik alınan önlemler [6].

Motor sonrasında hava kirliliğini azaltmaya yönelik önlem olarak kullanılan teknikler; egzoz gazı resirkülasyonu (EGR), termal reaktörler, oksidasyon katizörleri, üç yollu katalitik konvertörler (TWC) ve dizel motorlarında partikül tutuculardır [7]. Katalizörler, kendisi değişime uğramaksızın bir kimyasal reaksiyonun hız ve oranını değiştiren elemanlardır. Termodinamik olarak mümkün olan herhangi bir reaksiyonun hızı, düşük oranda bileşenlerin sıcaklığına bağlıdır. Reaksiyon hızları genellikle yüksek sıcaklıklarda artmaktadır. Katalizörler motor egzozunda oldukça yavaş ilerleyen reaksiyonları hızlandırarak emisyonların kontrol edilebilmesini sağlar [8]. Üç yollu katalitik konvertörde CO ve HC oksidasyonu ile $\mathrm{CO}_{2}$ ve $\mathrm{H}_{2} \mathrm{O}, \mathrm{NO}_{x}$ 'in indirgenmesi ile $\mathrm{N}_{2}$ oluşumunda birçok sayıda reaksiyon olmakla beraber bunların başlıcaları aşağıda belirtilen 7 farklı reaksiyon ile gösterilmektedir [6]. Şekil 1'de katalitik konvertörde gerçekleşen reaksiyonlar gösterilmiştir.

Oksidasyon reaksiyonlar1:

$$
\begin{aligned}
& \mathrm{CO}+1 / 2 \mathrm{O}_{2} \rightarrow \mathrm{CO}_{2} \\
& \mathrm{H}_{2}+1 / 2 \mathrm{O} 2 \rightarrow \mathrm{H}_{2} \mathrm{O} \\
& \mathrm{C}_{\mathrm{x}} \mathrm{H}_{\mathrm{y}}+(\mathrm{x}+\mathrm{y} / 4) \mathrm{O}_{2} \rightarrow \mathrm{x} \mathrm{CO}_{2}+\mathrm{y} / 2 \mathrm{H}_{2} \mathrm{O}
\end{aligned}
$$

$\mathrm{NO}_{\mathrm{X}}$ indirgenmesi:

$$
\begin{aligned}
& 2 \mathrm{CO}+2 \mathrm{NO} \rightarrow 2 \mathrm{CO}_{2}+\mathrm{N}_{2} \\
& \mathrm{C}_{\mathrm{x}} \mathrm{H}_{\mathrm{y}}+(2 \mathrm{x}+\mathrm{y} / 2) \mathrm{NO} \rightarrow \mathrm{x} \mathrm{CO}_{2}+\mathrm{y} / 2 \mathrm{H}_{2} \mathrm{O}+(\mathrm{x}+\mathrm{y} / 2) \mathrm{N}_{2}
\end{aligned}
$$

Buhar Reforming (Steam Reforming):

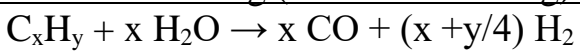

Su gaz değișimi:

$\mathrm{CO}+\mathrm{H}_{2} \mathrm{O} \rightarrow \mathrm{CO}_{2}+\mathrm{H}_{2}$

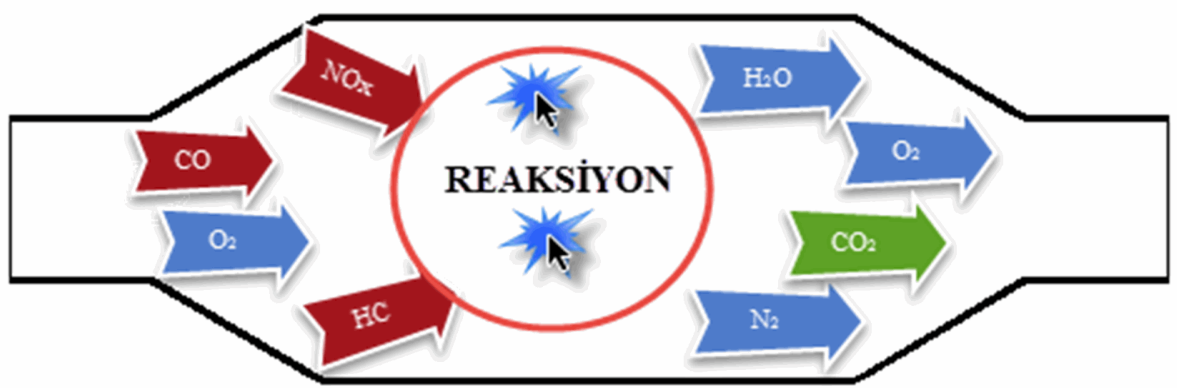

Şekil 1. Üç yollu konvertörlerde gerçekleşen kimyasal reaksiyonlar

Katalizörler çeşitli bileşiklerden oluşmaktadır. Yaygın olarak A12O3 gibi gözenekli oksitler diğer değerli metallere yataklık yapması için geniş yüzey alanı sağlamaktadır. Buna ek olarak Al2O3 katalizörün yüksek termal stabilitesini de artırır. Oluşturulan petek yap1 malzemenin yüzeyindeki kayıpları önlemek için baryum oksitlerden oluşan lantan malzemenin üstünde bir katman olarak 
bulunaktadır. Ayrıca asit metal dağılımının stabilize olması ve oksijen depolanması, buhar reformasyon reaksiyonlarını hızlandırmak için yükseltici olarak $\mathrm{CeO} 2$ ilave edilir. Geçtiğimiz son çeyrek yıllarda $\mathrm{ZrO} 2$ nin $\mathrm{CeO} 2$ ye ilave edilmesi oksijen depolanmasını ve elde edilen katalizörün 1s1l direncini önemli ölçüde artırdığı belirtilmiştir. Katalizörde elde edilen bu yapı son katmanı olarak Pd (Paladyum), Pt (Platin) ve Rh (Rodyum) gibi değerli metaller aktif katalizör partikülleri olarak en üst katmanı oluşturmaktadır. Bu değerli metaller standart bir katalizörde 2-5.5 gr civarında bulunmaktadır $[9,10,11]$. Pomza, açık renkli, boşluklu, süngerimsi, volkanik olaylar neticesinde oluşmuş, fiziksel ve kimyasal etkenlere karşı dayanıklı, gözenekli, silisli volkanik bir kayaçtır. Bir başka deyişle pomza, yoğun boşluk bulunan volkanik camsı bir taştır [12]. Ortalama ergime noktası $1343{ }^{\circ} \mathrm{C}$ 'dir. $760{ }^{\circ} \mathrm{C}$ 'nin altında herhangi bir hacim değişikliğine uğramaz. Bu sıcaklıkta dış yüzeydeki lifler buruşur ve çekilir. $480{ }^{\circ} \mathrm{C}$ ile $650{ }^{\circ} \mathrm{C}$ aralığındaki alevlerde pomza yapısal bozulma ve parçalanmaya uğramaz. Kayacın içerdiği $\mathrm{SiO}_{2}$ oranı, kayaca abrasif (aşındırıcı) özellik kazandırmaktadır. Bu yüzden çeliği bile rahatlıkla aşındırabilecek bir kimyasal yapı sergileyebilir. $\mathrm{Al}_{2} \mathrm{O}_{3}$ bileşimi ise ateşe ve 1 sıya yüksek dayanım özelliği kazandırır [13]. İçeriğindeki $\mathrm{Na}_{2} \mathrm{O}$ ve $\mathrm{K}_{2} \mathrm{O}$ tekstil sanayiinde reaksiyon özellikleri veren bileşimler olarak bilinmektedir [14]. Pomza; gözenekli yapısı, kristal suyu ihtiva etmemesi ve hiç bir işlem görmeden doğal olarak kullanılabilmesi pomza taşına oldukça fazla avantaj kazandırmaktadır. Pomza taşının doğal hafifliği diğer yabancı maddelerden arındırma işleminde çok büyük kolaylık sağlamaktadır. İlaç ve boya sanayi, içme suyu, muhtelif gıda suları, muhtelif yağların, glikoz ve fruktozun filtre edilmesinde kullanılmaktadır. Filtrelemede yaygın olarak kullanılan pomza, oluşumu sırasında bünyedeki gazların ani olarak bünyeyi terk etmesi ve ani soğuması nedeniyle, makro ölçekten mikro ölçeğe kadar sayısız gözenek içerir $[15,16]$. Gözenekler arası genelde bağlantısız boşluklu olduğundan geçirgenliği düşük, 1sı ve ses yalıtımı oldukça yüksektir [17,18].

Ülkemizde yaklaşık olarak rezervi 2,6 milyar $\mathrm{m}^{3}$ pomza madeni bulunmaktadır [19,20]. Pomza madeni yatakları yoğunlukla Doğu Anadolu bölgesinde Tatvan Bitlis sınırları içinde bulunmaktadır. Bu çalışma da, Bitlis ili sınırları içerisinde rezerv miktarı yüksek olan pomza madeninin katalitik konvertör katalizörü olarak kullanılmasının dizel motorlu araçlardan kaynaklanan egzoz kirleticilerinin önlenmesinde kullanılması durumunda azaltıcı etkisi belirlenmeye çalışılmıştır. Pomzanın kullanılmasında yapısındaki oksitli bileşiklerin fazla olması 1sı direnci ve ses yalıtım özelliğinden faydalanılması amaçlanmıştır. Ayrıca pomza madeni rezervlerinin her sektörde olduğu gibi otomotiv sektöründe de etkin olarak kullanılabilirliğinin olması amaçlanmıştır.

\section{Materyal ve Metot}

Yapılan çalışmada, belirli bir düzen ile yerleştirilen pomza taşları içerisinden egzoz gazlarının geçişini sağlamak için sitem tasarlanmış ve deney düzeneğine ilave edilmiştir. Egzoz gazlarının 1sı ve sıcaklığını ve ayrıca olası art yanmalar sonucu egzoz çıkışında oluşabilecek alevin doğrudan pomza taşlarına teması durumunda taşta oluşabilecek hasarın engellenmesi amacıyla, egzoz çıkışına alev sönümleyici ilave edilmiştir. Oksidasyon katalizörü olarak kullanılacak pomza taşı ve standart katalist Şekil 2' de verilmiştir.

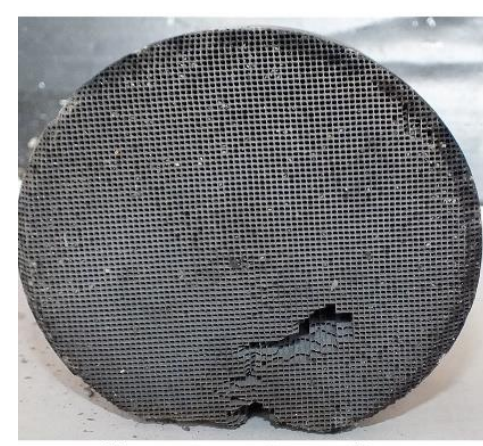

Standart katalist

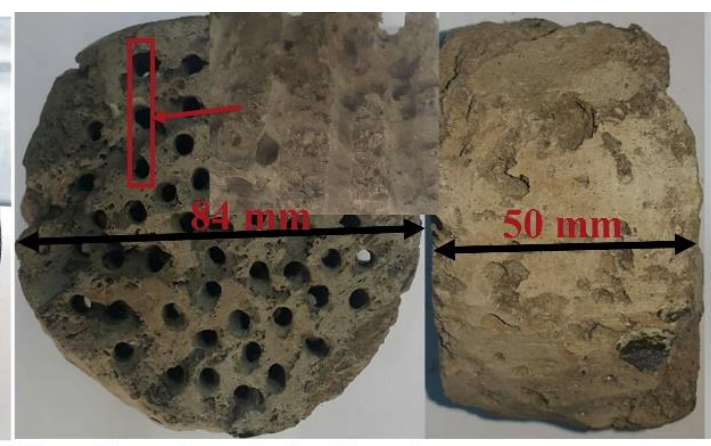

Katalist olarak kullanılan pomza taşı Test sonrası pomza taşı

Şekil 2. Testler esnasında kullanılan standart katalist ve pomza taşlarının görünümü 
Pomza taşının doğal olarak yapısında bulunan kılcal kanallarla bu sayede daha fazla yüzey alanı oluşturulmak hedeflenmiştir. Oksidasyon katalizörü olarak kullanılan saf pomza taşının genel kimyasal bileşimi Tablo 1'de verilmiştir [20].

Tablo 1. Pomza'nın Genel Kimyasal Bileşimi

\begin{tabular}{cccc}
\hline Bileşen & İçerik (\%) & Bileşen & İçerik (\%) \\
\hline $\mathrm{SiO}$ & $60-75$ & $\mathrm{Na}_{2} \mathrm{O}+\mathrm{K}_{2} \mathrm{O}$ & $7-8$ \\
$\mathrm{~A}_{2} \mathrm{O}_{2}$ & $13-15$ & $\mathrm{TiO}_{2}$ & Eser \\
$\mathrm{Fe}_{2} \mathrm{O}_{3}$ & $1-3$ & $\mathrm{SO}$ & Eser \\
$\mathrm{CaO}$ & $1-2$ & $\mathrm{Cl}$ & Eser \\
$\mathrm{MgO}$ & $1-2$ & & \\
\hline
\end{tabular}

Motor testleri Bitlis Eren Üniversitesi Teknik Bilimler Meslek Yüksekokulu Motorlu Araçlar ve Ulaştırma Teknolojileri Bölümü Laboratuvarında yapılmıştır. Motor test standı Şekil 2'de görülmektedir. Test sisteminde $26 \mathrm{~kW}, 80 \mathrm{Nm}$ tork ve max $5000 \mathrm{rpm}$ hızında elektrikli dinamometre kullanılmaktadır. Test sisteminde yakıt tüketimi, motor momenti ve motor gücü verileri anlık olarak, kullanılan arayüz programı ile dijital olarak kaydedilmiştir. Testler tek silindirli dört zamanlı, sıkıştırma ile ateşlemeli motorda tam gaz konumunda altı farklı motor yükünde test edilmiştir. Tablo 2'de kullanılan motorun özellikleri verilmiştir. Egzoz emisyonları Mobydic marka gaz analiz cihazı kullanılarak kayıt altına alınmıştır. Kullanılan cihazın ölçüm aralıkları Tablo 3'de verilmiştir. Kullanılan yakıt deneylere başlanmadan önce yeterli miktarda piyasadan temin edilmiştir. Elde edilen sonuçlar aynı şartlarda piyasadan temin edilen ve günümüzdeki araçlarda kullanılan katalitik konvertörde bulunan katalizör ile grafiksel olarak karşılaştırılmıştır.

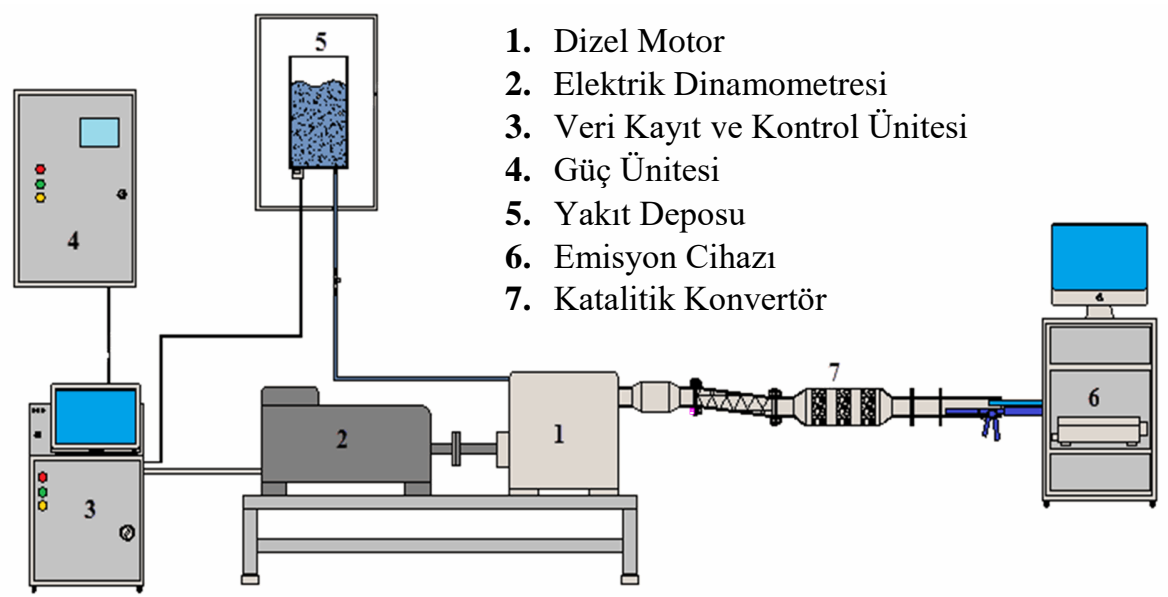

Şekil 3. Deney düzeneğinin şematik görünümü

Tablo 2. Test motoru özellikleri

\begin{tabular}{ll}
\hline Motor Tipi & ANTOR 3 LD 510 \\
\hline Silindir Sayısı & 1 \\
Silindir Çapı x Strok & $85 \times 90 \mathrm{~mm}$ \\
Silindir Hacmi & $510 \mathrm{~cm}^{3}$ \\
Sikıştırma Oranı & $17: 01$ \\
Maksimum Motor Devri & $3200 \mathrm{~d} / \mathrm{dk}$ \\
Maksimum Motor Gücü & $12 \mathrm{Hp}$ \\
Maksimum Motor Momenti & $3,5 \mathrm{~kg} \cdot \mathrm{m} 1800 \mathrm{~d} / \mathrm{dk}$ \\
\hline
\end{tabular}


Tablo 3. Emisyon cihazı özellikleri

\begin{tabular}{ll}
\hline \multicolumn{2}{l}{ MOBYDIC 5000 GAZ ANALİ CiHAZI } \\
\hline $\mathrm{CO} \%$ Vol & $0-10$ \\
$\mathrm{CO}_{2} \%$ Vol & $0-20$ \\
$\mathrm{HC} \mathrm{ppm} \mathrm{Vol}$ & $0-20000$ \\
$\mathrm{O}_{2} \%$ Vol & $0-21$ \\
$\mathrm{NO}_{\mathrm{x}} \mathrm{ppm}$ & $0-5000$ \\
Lambda & $0-5$ \\
$\mathrm{~N} \%$ & $0-100$ \\
$\mathrm{~K} 1 / \mathrm{m}$ & $0-20$ \\
Partikül mg/m & $0-1000$ \\
\hline
\end{tabular}

\section{Bulgular ve Tartışma}

Şekil 4'de motor hızına göre motor performans eğrileri değişimi görülmektedir. Şekil 4 incelendiğinde standart katalizör kullanımı ile pomza kullanımı arasında motor gücünde az bir miktar değişim olduğu görülmektedir. Motor gücü motor devri ve momentine bağlı olarak değișen bir büyüklüktür. Bu durum motor momentindeki azalama ile ilişkilidir. Yüksek motor devirlerinde silindir içerisine alınan hava miktarı ve silindir içerisinde kalan yanmış gaz miktarı etkilemektedir. Katalitik konvektör kullanımında egzoz gazları katalizör içerisinden geçtiği için bu durum motora artı bir yük getirmektedir. Bu durum motor momentinde ve gücünde az da olsa bir miktar azalmaya, özgül yakıt tüketiminde (ÖYT) ise artışa sebep olmaktadır. Motor momentindeki bu azalma maksimum motor devrinde standart katalizör kullanımında \%3 pomza kullanımında ise yaklaşık \%4 olarak tespit edilmiştir. Motor gücünde ise standart katalizör kullanılmasında maksimum \%1 pomza kullanımında ise maksimum $\% 4$ oranında bir azalma olduğu görülmektedir. Motor gücünün azalması özgül yakıt tüketiminin artmasına sebep olmaktadır. Bu artışın standart katalizör kullanımında yaklaşık \%1, pomza kullanımında ise yaklaşık $\% 3$ oranında olduğu tespit edilmiştir.

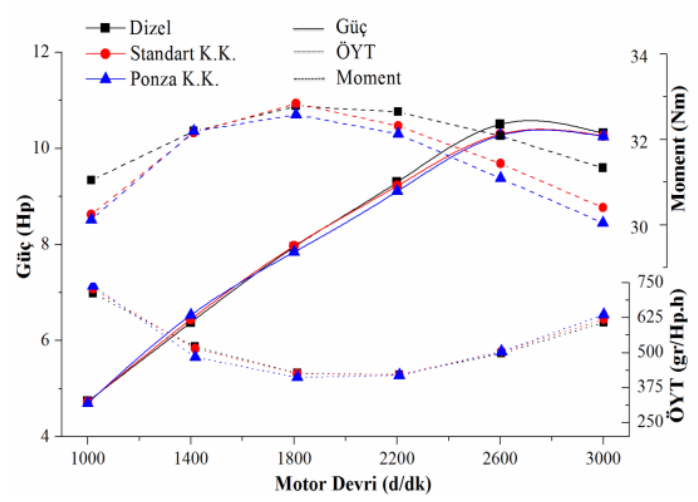

Şekil 4. Motor hızına göre motor performans değişimi

Şekil 5'de değişen motor hızına göre HC emisyonlarının değiş̧imi verilmiştir. Silindir içerisine püskürtülen yakıt yanma sonlandığında yeterli oksijen bulamadığı için egzoz gazları içerisinde HC oluşturur [21]. Şekil 5 incelendiğinde motor yüküne bağlı olarak HC emisyonlarının arttığ görülmektedir. Maksimum HC emisyonu $1000 \mathrm{~d} / \mathrm{dk}$ motor hızında katalizör kullanılmadan alınan ölçümde 62 ppm olarak kaydedilmiştir. Aynı motor devrinde standart katalizör kullanımında 40 ppm, katalizör yerine pomza kullanımında ise 57 ppm olarak elde edilmiştir. Bütün motor devirlerinde ve aynı şartlarda katalizör olarak pomza kullanımında HC emisyonlarında katalizör kullanılmadan elde edilen HC emisyonlarına göre azalma olduğu görülmektedir. Bütün motor devirlerinde elde edilen değerlerin ortalaması alındığında standart katalizör kullanımında $\% 49,15$ oranında bir azalma ve aynı şartlarda pomza kullanımında ise \%19 oranında bir azalma olduğu görülmektedir. Bu azalma (1) ve (2) numaralı denklemlerle açıklanabilir. Egzoz gazları içerisindeki HC'ların oksidasyon filtresi içerisinde oksijenle tepkimeye girerek (1 numaralı denklem) oksitlenmesi sonucu $\mathrm{CO}_{2}$ ve $\mathrm{H}_{2} \mathrm{O}$ 'ya dönüşmektedir [6]. 
1 numaralı denklemin ürünü olan $\mathrm{H}_{2} \mathrm{O}$ kullanılarak $\mathrm{HC}$ 'ler $\mathrm{CO}$ ve $\mathrm{H}_{2}$ (2 numaralı denklem) gazlarına dönüştürülmektedir.

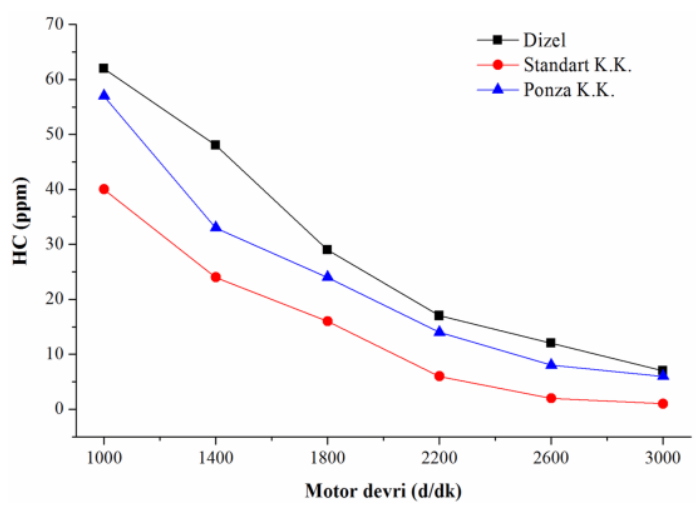

Şekil 5. Motor hızına göre HC emisyon değişimi

Şekil 6'da motor hızına göre CO emisyonu değişimi verilmiştir. Grafik incelendiğinde CO değişimi motor devrinin artmasıyla azaldığı görülmektedir. Maksimum CO emisyonu $1000 \mathrm{~d} / \mathrm{dk}$ katalizörsüz olarak 2,71, standart katalizör kullanımında 1,71 ve katalizör olarak pomza kullanımında ise 2,6 olarak ölçülmüştür. CO emisyonundaki bu azalma; (3), (4) ve (5) nolu reaksiyon denklemlerinin gerçekleşmesi ile sağlanabilir [6]. Bilindiği üzere dizel motorlarda (hava fazlalık katsayısı) HFK $>1$ şeklindedir. $\mathrm{Bu}$ durumda silindir içerisinde yanma reaksiyonuna katılamayan fazladan hava bulunmaktadır. Silindirde yanma reaksiyonuna girmeyen oksijen ve $\mathrm{NO}_{\mathrm{X}}$ indirgenmesi sırasında açığa çıkan oksijen, katalizörde $\mathrm{CO}$ ile reaksiyona girerek $\mathrm{CO}_{2}$ oluşturmaktadır [22]. Pomza taşı oksitleyici olarak kullanılması durumunda 3 ve 4 numaralı reaksiyon denkleminin gerçekleştiği yani pomza taşının yapısındaki oksitli bileşikler reaksiyonda daha etkili olmuştur. $\mathrm{CO}$ emisyonu oksitlenmesinde kullanılan reaksiyonlarda 5 numaralı reaksiyon etkisinin fazla olmadığ 1 söylenebilir. 5 numaralı reaksiyon denkleminde $\mathrm{NO}_{\mathrm{x}}$ gazlarının indirgenmesiyle elde edilen NO kullanılmaktadır. Nitekim katalizör olarak pomza kullanılması durumunda $\mathrm{NO}_{\mathrm{x}}$ emisyonlarının indirgenme reaksiyonunda tepkime oluşturan platin, paladyum gibi değerli metallerin bulunmaması bu reaksiyonun gerçekleşmemesini doğrudan etkilemektedir.

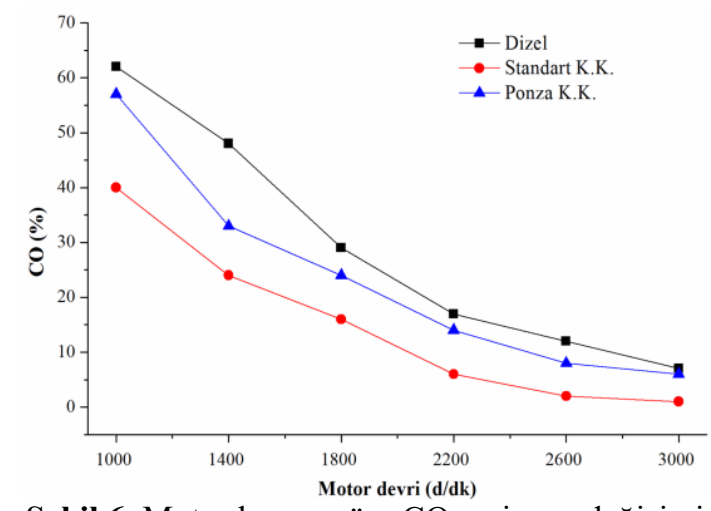

Şekil 6. Motor hızına göre CO emisyon değişimi

Şekil 7'de motor hızına göre is emisyonu değişimi verilmiştir. Dizel motorlardan kaynaklı olan is emisyonunun büyük bir kısmı karbon parçacıkları diğer kısmı ise hidrokarbonlardan oluşmaktadır [23]. Şekil incelendiğinde artan motor devriyle is emisyonlarının azaldığ 1 görülmektedir. Ayrıca yüksek motor devirlerinde $(2600 \mathrm{~d} / \mathrm{dk}$ ve $3000 \mathrm{~d} / \mathrm{dk})$ katalizör olarak pomza kullanımında ise dönüşüm veriminin arttığı görülmektedir. Maksimum is emisyonu maksimum motor yükünde katalizör kullanılmaması durumunda elde edilmiştir. Bu motor devrinde $(1000 \mathrm{~d} / \mathrm{dk})$ katalizörsüz 4,54 standart katalizör kullanımında 4,11 ve pomza kullanımında ise 4,41 olarak kaydedilmiştir. İs emisyonundaki maksimum azalma $2600 \mathrm{~d} / \mathrm{dk}$ ve $3000 \mathrm{~d} / \mathrm{dk}$ motor devirlerinde olduğu görülmüştür. $\mathrm{Bu}$ dönüşüm veriminin değişimi sıcaklıkla ve gaz kompozisyonu ile ilgilendirilebilir. Yanma sonu sicaklığı 1400 ${ }^{\circ} \mathrm{C}$ 'nin altına düştüğünde silindir içerisindeki is oksitlenmesi etkisini kaybetmektedir [4]. Motor 
yükünün azalmasıyla egzoz gaz sıcaklığının artması oluşan egzoz gazı içerisindeki is konsantrasyonunu azaltmakta ve sıcaklığın artması ile is emisyonu içerisindeki karbonların katalizör oksitlenmesi de artmaktadır.

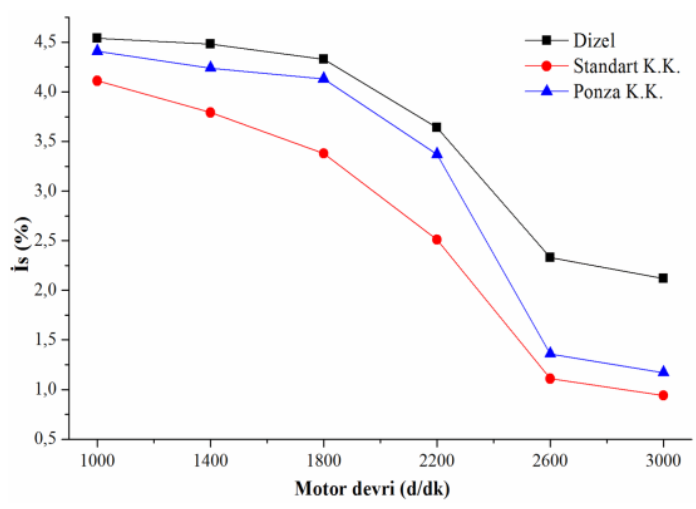

Şekil 7. Motor hızına göre is emisyon değişim

Şekil 8'de motor hızına göre $\mathrm{CO}_{2}$ emisyonu değişimi verilmiştir. Şekil incelendiğinde artan motor devriyle $\mathrm{CO}_{2}$ emisyonun azaldığı görülmektedir. Ancak katalizör olarak pomza kullanımında katalizörsüz elde edilen sonuçlara göre $\mathrm{CO}_{2}$ emisyonlarında artış olduğu ve standart katalizör kullanımı ile bu artışın maksimum seviyelere çıktığı görülmektedir. Katalizör olarak pomza kullanımında $\mathrm{CO}_{2}$ emisyonlarındaki artış standart katalizör kullanıldığında elde edilen $\mathrm{CO}_{2}$ emisyonlarına yakın seviyelere ulaştığı görülmektedir. Bütün motor devirlerindeki elde edilen verilerin ortalaması alındığında, $\mathrm{CO}_{2}$ emisyonunun katalizör kullanılmaması durumunda \% 7,73, standart katalizör kullanımında \%10,44 ve katalizör olarak pomza kullanımında ise \% 9,64 olduğu görülmektedir. $\mathrm{CO}_{2}$ emisyonu değişimi egzoz gazları konsantrasyonunda katalitik konvertörde reaksiyonların gerçekleştiğini göstermektedir.

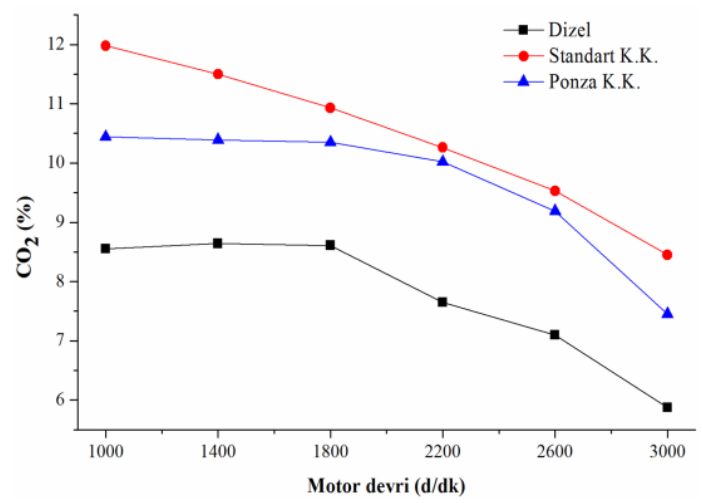

Şekil 8. Motor hızına göre $\mathrm{CO}_{2}$ emisyon değişimi

Şekil 9'da $\mathrm{NO}_{\mathrm{x}}$ emisyonu değişimi veriliştir. NO dizel motorlarda NOx' un ana bileşenidir. Azotun yüksek sıcaklıkta ve zengin oksijen miktarı ile reaksiyonunun bir ürünüdür. İki önemli NO oluşum mekanizmas1 vardır. Bunlardan birincisi 1sısal NO, ikincisi zengin $\mathrm{NO}$ oluşumudur. $\mathrm{Bu}$ mekanizmalardan ikincisi zengin yakıtlı sistemlerde yaygın olarak oluşmaktadır. Dizel motorlar fakir karışımla çalışan $(H F K>1)$ motorlar olduğu için, önemli bir NO kaynağı değildir [21]. Şekil 8 incelendiğinde motor devrinin artması ile $\mathrm{NO}_{\mathrm{x}}$ emisyonlarında artma olduğu görülmektedir. Maksimum motor devrinde, maksimum $\mathrm{NO}_{\mathrm{x}}$ emisyonu katalizör kullanılmaması durumunda 2795 ppm standart katalizör kullanılması durumunda 1548 ppm ve pomza kullanımında ise 2596 ppm olarak kaydedilmiştir. Ancak günümüzde araçlarda kullanılan katalizörler üç tabakadan oluşmaktadır. $\mathrm{Bu}$ tabakalardan en önemlisi ve $\mathrm{NO}_{\mathrm{x}}$ emisyonlarının indirgenmesi için üçüncü tabaka olan soy metaller (platin, paladyum, rodyum vb.) oluşturmaktadır [24]. $\mathrm{NO}_{\mathrm{X}}$ emisyonu standart katalizör kullanılması durumunda $2600 \mathrm{~d} / \mathrm{dk}$ ya kadar olan motor devirlerinde artış yönünde olduğu $2600 \mathrm{~d} / \mathrm{dk}$ motor devrinden sonraki motor devrinde ise daha sabit olduğu görülmektedir. Ayrıca katalizör olarak pomza kullanımında $2600 \mathrm{~d} / \mathrm{dk}$ motor devrinden sonraki motor devirlerinde grafik eğrisinin sabit olarak arttığ görülmektedir. Dinler vd. [7] yapıkları çalışmada katalitik konvertör kullanımında orta motor yüklerinde 
$\mathrm{NO}_{\mathrm{X}}$ emisyonlarına herhangi bir etkisinin olmadığı, artan motor yükü ile $\mathrm{NO}_{\mathrm{X}}$ emisyonları üzerinde etkili olduğunu belirtmişlerdir.

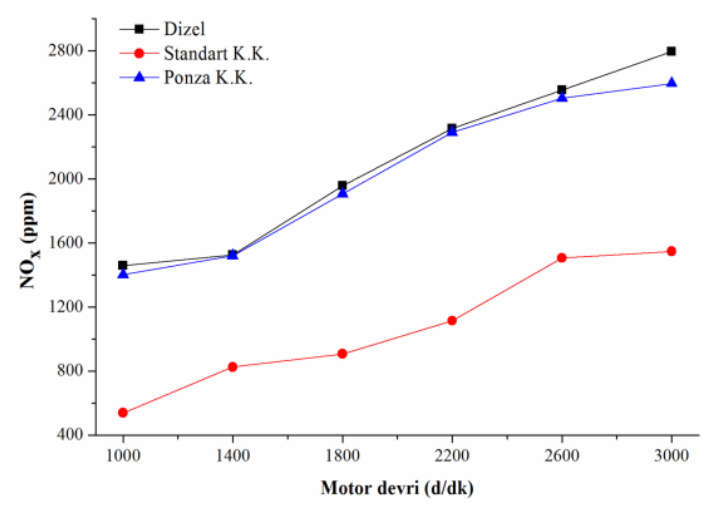

Şekil 9. Motor hızına göre $\mathrm{NO}_{\mathrm{X}}$ emisyon değişimi

Şekil 10'da motor hızına göre egzoz gaz sıcaklığı değiş̧imi verilmiştir. Şekilde de görüldüğüu üzere motor yükünün azalması ile artan motor devri aynı zamanda egzoz gaz sıcaklığının artmasına neden olmaktadır. Katalitik konvertör kullanımında egzoz sıcaklığının belirli oranda azaldığı görülmektedir. Ayrıca standart katalizör kullanılması durumunda $2600 \mathrm{~d} / \mathrm{dk}$ motor devrine kadar NOx emisyonu belirli oranlarda artmakta ve bu devirden sonraki motor devrinde ise artışın daha sabit olduğu görülmektedir. $\mathrm{Bu}$ durum egzoz gaz sıcaklığı ile ilişkilendirilmektedir. Katalitik konvertör içerisinde reaksiyonların gerçekleşmesi sıcaklığa ve egzoz gazları kompozisyona bağlı olarak değişmektedir Nitekim yapılan birçok çalışmada egzoz gazları içerisindeki oksidasyon ve indirgenme reaksiyon hızları sıcaklıkla değiştiği belirtilmektedir [7,11,22].

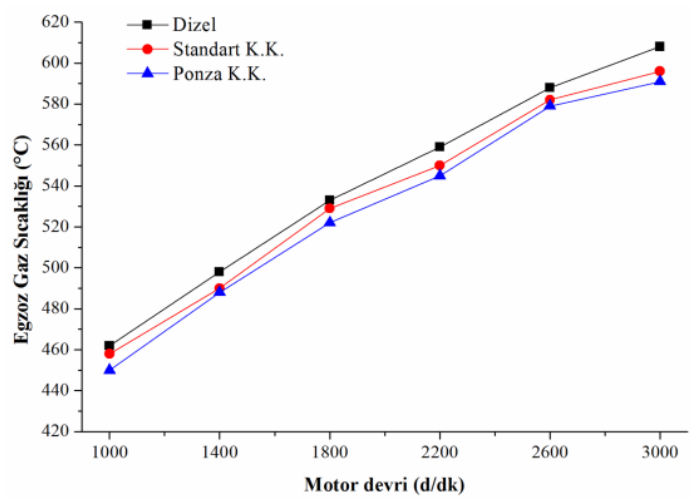

Şekil 10. Motor hızına göre egzoz gaz sıcaklığı değişimi

Şekil 11'de egzoz gazı dönüşüm verimleri verilmiştir. Standart katalizör kullanılmasında HC, CO ve $\mathrm{NO}_{\mathrm{x}}$ emisyonlarda yaklaşık \%50 oranında dönüşüm verimi olduğu görülmektedir. Standart katalizör kullanılmasında $\mathrm{CO}_{2}$ emisyonu dönüşümünün de yaklaşık $\% 25$ civarında olduğu bununla birlikte pomza kullanımında ise $\mathrm{CO}_{2}$ emisyonu dönüşüm verimi yaklaşık olarak \%20 civarında olduğu tespit edilmiştir. $\mathrm{CO}_{2}$ emisyonunun pomza kullanımında standart katalizör kullanımına yakın bir dönüşüm verimi sağlamasının sebebi NOx emisyonu indirgenmesinde; (6) ve (7) nolu reaksiyon denklemlerinin gerçekleşmesi ile sağlanabilir [6]. Reaksiyon denklemlerinde (6) numaralı denklemde $\mathrm{CO}_{2}$ gazının kullanılmasından dolayı standart katalizörde bu $\mathrm{CO}_{2}$ emisyon gazının daha az salınmasından kaynaklanmaktadır. 


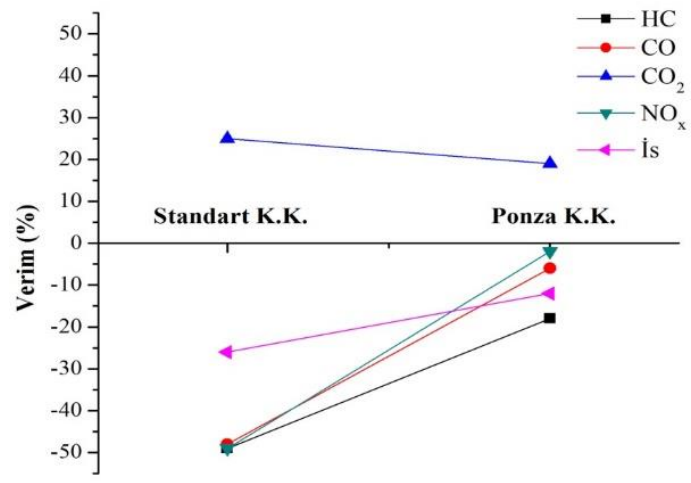

Şekil 11. Egzoz Gazı Dönüşüm Verimi

\section{Sonuç ve Öneriler}

İşlenmemiş pomza madeninin katalitik konvertör katalizörü olarak kullanılabilirliği deneysel olarak incelenmiş ve aşağıdaki sonuçlar elde edilmiştir.

- Pomza madeni katalitik konvertör katalizörü olarak kullanımının yaklaşık olarak HC ve CO emisyonlarında sırası ile maksimum $\% 19$ ve $\% 6$ oranında bir dönüşüm verimi olduğu görülmüştür.

- Pomza madeninin katalizör olarak kullanımı durumunda is emisyonlarında ise bu dönüşüm verimi $\% 12$ olduğu görülmüştür. Ancak motor devrinin artması ile bu verimin değiştiği ve yaklaşık $\% 44$ 'lere kadar çıktı görülmektedir. Ayrıca pomza madeninin gözenekli yapısı ile partikül filtresi görevi de görmektedir.

- $\quad \mathrm{NO}_{\mathrm{X}}$ emisyonlarında ise pomza madeni kullanımında dönüşüm veriminin \%2-3 oranında olduğu görülmektedir. $\mathrm{Bu}$ durum olumsuz olarak nitelendirilebilir. Pomza madeni katalizör olarak değerlendirilmesi durumunda bazı soy metaller ile desteklenmesi $\mathrm{NO}_{\mathrm{X}}$ emisyonunun indirgenmesinde de etkili olacağı söylenebilir.

- Bölgede bulunan bu madenin farklı sektörlerde değerlendirildiği gibi otomotiv sektöründe de değerlendirilmesi hem ülkemize hem de bölgemize artı bir katma değer olacaktır.

- Sonuçlarda ayrıca motor egzoz ses düzeyinde işitsel olarak bir azalma olduğu tespit edilmiştir. Bu özellikle şehir içi araç kullanımında oluşan gürültü kirliliğinin de azaltılması amacıyla da kullanılabilir.

- Pomza madeninin büyük parça olarak kullanılması haricinde farklı boyutlarda granüler olarak kullanımı ile hem büyük parçalı kullanımında ihtiyaç duyulan delik delme işlemine de gerek kalmayabilir, hem de katalizör olarak kullanımında yüzey alanı artıılarak daha verimli sonuçlar elde edilebilir.

- Pomza madeni değişik oksitleyici elementler ile desteklenerek verim artırmaya yönelik yenilikler araştırılabilir.

- $\mathrm{NO}_{\mathrm{X}}$ emisyonlarının azaltılmasına yönelik çalışmalarda pomza madeni farklı yöntemlerle Paladyum, Rodyum ve Platin gibi soy metallerle desteklenerek $\mathrm{NO}_{\mathrm{x}}$ emisyonları üzerine etkisi araştırılabilir.

- Pomza iri toz halinde farklı metal ve oksitleyici elementlerle desteklenerek farklı geometrilere sahip katalizör üretimi ve dönüşüm verimi araştırılabilir.

\section{Kaynaklar}

1. Alkaya B., Yıldııım M.A. 2000. Taşıt Kaynaklı Kirleticilerin Azaltılma Yöntemleri, Ekoloji Çevre Dergisi, 9 (34): 15-20.

2. Işı1ksoluğu M.A. 1997. Dizel Motorlu Taşıtların Egzoz Gazındaki Duman Koyuluğu ve Ölçümünde Karşılaşılan Sorunlar, Mühendis ve Makine Dergisi, 453 (7): 21-25. 
3. Çakıroğlu M. 1996. Motorlu Taşıt Trafiğinde Egzoz Emisyonları, I. Ulusal Ulaşım Sempozyumu, İstanbul.

4. Haşimoğlu C., İçingür Y., Öğüt H. 2002. Dizel Motorlarında Egzoz Gazları Re sirkülasyonunun (EGR) Motor Performans1 ve Egzoz Emisyonlarına Etkisinin Deneysel Analizi, Tübitak Dergisi, 26: $127-135$.

5. Kelen F. 2014. Motorlu Taşıt Emisyonlarının İnsan Sağlı̆̆ı ve Çevre Üzerine Etkileri, Yüzüncü Yı1 Üniversitesi Fen Bilimleri Enstitüsü Dergisi, 19 (1-2): 80-87.

6. Kutlar A., Ergeneman M., Arslan H., Mutlu M. 1998. Taşıt Egzozundan Kaynaklanan Kirleticiler. Birsen Yayınevi, İstanbul.

7. Dinler N., Yücel N. 2003. Karbüratörlü Bir Motora Üç Yollu Katalitik Konvertör Uygulanmas1, Gazi Üniversitesi Mühendislik ve Mimarlık Fakültesi Dergisi, 18 (1): 57-70.

8. Gökmen M.S. 2014. Yanma - Emisyon Modellerinin İncelenmesi ve Diesel Motorlarda SCR Sistemleri. Selçuk Üniversitesi Fen Bilimleri Enstitüsü, Yüksek Lisans Tezi, Konya.

9. Ertl G., Knözinger H., et al. 1997. Handbook of Heterogeneous Catalysis. Wiley-VCH, Weinheim.

10. Kaspar J., Fornasieo P., Hickey N. 2003. Automotive Catalytic Converters: Current Status and Some Perspective, Catalysis Today, 77: 419-449.

11. Lassi U., Polvinen R., Suhonen S., Kallinen K., Savimaki A., Harkönen M. et al. 2004. Effect of Ageing Atmosphere on the Deactivation of $\mathrm{Pd} / \mathrm{Rh}$ Automotive Exhaust Gas Catalysts: Catalytic Activity and XPS Studies, Applied Catalysis A: General, 263: 241-248.

12. Brito A., Garcia F., Alvarez C., Arvelo R., Fierro J.L.G., Diaz C., 2004. High Surface Area Support/Catalyst Derived from Natural Pumice, Study of Pretreatment Variables, Ind. Eng. Chem. Res. 43 (7): 1659-1664.

13. Farizoglu B., Nuhoglu A., Yildiz E., Keskinler B., 2003. The Performance of Pumice as a Filter Bed Material under Rapid Filtration Conditions, Filtr. Sep. 40 (3): 41-46.

14. Özkan Ş.G., Tuncer G. 2001. Pomza Madenciliğine Genel Bir Bakış, 4. Endüstriyel Hammaddeler Sempozyumu, pp200-207, İzmir, Türkiye.

15. Aruna S.T., Roy S., Sharma A., Savitha G., Grips V.W. 2014. Cost-effective Eear and Oxidation Resistant Electrodeposited Ni-pumice Coating, Surface and Coatings Technology, 251: 201-209.

16. Gungor N., Tombul M., 1997. The Usage of Pumice and the Effect of Legislation on Pumice Mining, First Isparta Pumice Symposium, pp85-90, Isparta, Turkey.

17. Wesley L.D., 2001. Determination of Specific Gravity and Void Ratio of Pumice Materials, Geotech. Test. J. 24 (4): 418-422.

18. Sekizinci Beş Yıılık Kalkınma Planı. 2001. Madencilik Özel İhtisas Komisyonu Raporu Endüstriyel Hammaddeler Alt Komisyonu Yapı Malzemeleri III Çalışma Grubu Raporu, Ankara.

19. Gunduz L., Sariisik A., Tozacan B., Davraz M., Ugur I., Cankiran O., 1998. Pumice Technology, vol. 1. S (in Turkish).

20. Köse H., Pamukçu Ç., Yalçın N., Seçer T. 1997. Pomza ve Yapı Malzemesi Olarak Kullanım Olanaklar1, 2. Endüstriyel Hammaddeler Sempozyumu, İzmir.

21. Baskar A., Senthilkumar A. 2016. Effects of Oxygen Enriched Combustion on Pollution and Performance Characteristics of a Diesel Engine, Engineering Science and Technology, An International Journal, 19 (1): 438-443.

22. Özsezen A.N., Eyidoğan M., Türkcan A., Alptekin E., Şanlı A., Çanakcı M., Kılıçaslan İ. 2009. Binek Tipi Bir Taşıtta Katalitik Konvertör Veriminin Deneysel Olarak İncelenmesi, Electronic Journal of Vehicle Technologies, 1 (1): 1-7. 
23. Keskin A., Sağıroğlu S. 2010. Dizel Motorlarından Kaynaklanan Egzoz Emisyonları Ve Kontrol Yöntemleri, Mühendis ve Makina, 51 (606): 1-8.

24. Aydoğan B. 2008. Biyodizel Kullanılan Dizel Motorlarda $\mathrm{NO}_{\mathrm{x}}$ Emisyonlarının ve $\mathrm{NO}_{\mathrm{x}}$ Emisyonları Azaltma Yöntemlerinin İncelenmesi. PAÜ, Fen Bilimleri Enstitüsü, Makine Mühendisliği Anabilim Dalı, Yüksek Lisans Tezi, 81s, Denizli. 